\title{
Leading the charge? Payments for single use carrier bags in Wales
}

\author{
LORI Frater AND Robert G LeE
}

\author{
ESRC Research Centre for Business Relationships, Accountability, \\ Sustainability and Society, Cardiff University
}

\section{Introduction}

$\mathrm{O}$ 1 October 2011, the Welsh government (WG), employing powers conferred by ss 77 and 90 of and Schedule 6 to the Climate Change Act 2008 (the Act), ${ }^{1}$ introduced the first mandatory charge for single use carrier bags in the UK through the implementation of the Single Use Carrier Bag Charge (Wales) Regulations $2010^{2}$ (the Regulations). Under the Regulations, retailers are required to charge a minimum of $5 p$ for all single use carrier bags, which meet the definitional requirements laid down in the Regulations. This definition includes plastic, paper, biodegradable and recyclable carrier bags. All retailers, not only those retailers that sell food and groceries, are affected by the Regulations, which apply equally to sales in store and online. The Regulations extend to goods purchased in Wales and goods delivered in a single use carrier bag to someone in Wales. Wales was the first of the devolved administrations to introduce such a scheme, though the Republic of Ireland introduced a nationwide charge for plastic carrier bags as long ago as 2002. ${ }^{3}$ At the time of writing, consultations on similar schemes are underway in Scotland and recently concluded in Northern Ireland. This paper considers this activity on the part of devolved administrations in the UK. It then draws on our two empirical studies to analyse the experiences of the implementation process in Wales of both the general public and of retailers whose behaviour is effectively regulated by the change. It concludes with some reflections on introducing legislative change which will affect the everyday behaviour of the population as a whole. It opens, now, with a consideration of why one might want to reduce the number of single use carrier bags in circulation.

It is estimated that $500 \mathrm{bn}$ plastic carrier bags are used worldwide each year. ${ }^{4}$ In the UK alone, in 2010 there were approximately 6.8bn plastic bags handed out by retail shops. In 2009 , an estimated $445 \mathrm{~m}$ carrier bags were used by shoppers from the major supermarkets

1 The Act extends to both England and Wales.

22010 No 2880 (W 238) as amended by Single Use Carrier Bags Charge (Wales) (Amendment) Regulations 2011 (2011 No 2184 (W 236)).

3 SI No 605/2001 Waste Management (Environmental Levy) (Plastic Bag) Regulations, 2001 made under the Waste Management Acts 1996 and 2001 and see F Convery, F McDonnell and S Ferreira, 'The Most Popular Tax in Europe? Lessons from the Irish Plastic Bags Levy' (2007) 38 Environment and Resource Economics 1-11.

4 K A Spokas, 'Plastics: Still Young, but Having a Mature Impact' (2007) 28(3) Waste Management 473-4 and 'Waste: An Overview' (2005) 77(9) Geographical 34-35. 
in Wales ${ }^{5}$ which equates to 273 bags per household. On average, every kilogram of litter collected contains 3.4 plastic bags, ${ }^{6}$ constituting around 2.7 per cent by weight of all litter and costing Welsh local authorities an estimated $f, 1 \mathrm{~m}$ to clean up plastic bag litter every year. ${ }^{7}$ Many single use carrier bags are made of oil-based plastic, which is a non-renewable resource and can take up to 500-1000 years to decompose. The United Nations Environment Programme estimates that there are 46,000 pieces of plastic litter floating in every square mile of ocean. ${ }^{8}$

It is no accident that the powers to tackle carrier bag use in England and Wales are contained in the Climate Change Act 2008. A large amount of harmful emissions are produced during manufacture, shipment and recycling of plastic bags. Paper carrier bags, which are often considered a more environmentally friendly alternative, also have environmental consequences as much of the pulp used for paper shopping bags is virgin pulp because it is considered stronger. Paper production requires hundreds of thousands of gallons of water as well as toxic chemicals like sulphurous acid, which can lead to acid rain and water pollution. Even paper bags that come from a renewable source and are biodegradable require more energy than plastic bags to manufacture and transport. A report published by the Environment Agency estimates that rather than use a plastic carrier bag just once, we need to use a paper bag three times to match the global-warming potential.?

\section{Enabling provisions and devolved government}

The Climate Change Act 2008 introduces a long-term legally binding framework to tackle the dangers of climate change. The central pillars of the legislation are legally binding targets for reducing emissions of greenhouse gases (GHG) by 2020 and $2050 .{ }^{10}$ The Act aims for a built-in series of duties, actions and reports, which, whilst not necessarily enforceable in their own right, ${ }^{11}$ create the transparency, accountability and political pressure necessary to achieve the purpose of the legislation.

Powers to introduce a charge for carrier bags are contained in Part 5 of the Act, alongside supporting provisions aimed at reporting on, measuring and reducing carbon emissions in different sectors of the economy and society. Schedule 6 of the Act enabled the WG to introduce a minimum charge for carrier bags but not a maximum charge. ${ }^{12}$ Schedule 6 is silent as to where the proceeds of the charge should be directed. Between the passage of the 2008 Act and the time that Wales began to plan to act on carrier bags, it had acquired additional legislative competence. The Government of Wales Act 2006 had

5 WG (2010) Proposal for a Charge on Single Use Carrier Bags: A Consultation on the Draft Single Use Carrier Bag Charge (Wales) Regulations 2010, June 2010.

6 Waste Awareness Wales, 2011 <www.wasteawarenesswales.org.uk/recycle/plastic_bags.html>.

7 WG (n 5).

8 United Nations Environment Programme (2006), UNEP-IUCN, Ecosystems and Biodiversity in Deep Waters and High Seas, UNEP Regional Seas Report and Studies No 178.

9 Environment Agency (2011), Evidence: Life Cycle Assessment of Supermarket Carrier Bags: A Review of the Bags Available in 2006 Report SC030148.

10 Client Earth (CE), The UK Climate Change Act 2008: Lessons for National Climate Laws (CE November 2009).

11 Cf Friends of the Earth and Ors $v$ Secretary of State for Energy [2009] EWCA Civ 810 and see M Stallworthy, 'Legislating against Climate Change: A UK Perspective on a Sisyphean Challenge' (2009) 72 Modern Law Review 412-36

12 See Schedule 6 para 4. 
introduced a certain competence to legislate in environmental matters ${ }^{13}$ and, following the National Assembly for Wales (Legislative Competence) (Environment) Order 2010, the National Assembly was able to make provision (inter alia) relating to preventing, reducing, collecting, managing, treating or disposing of waste. This it did by the Waste (Wales) Measure 2010 and that measure amended Schedule 6 of the 2008 Act in relation to the destination of proceeds from the charge in Wales by inserting a new para 4A. That paragraph allows the Welsh ministers to provide for the application of the net proceeds of the charge to specified purposes.

In spite of the passage of the 2008 Act, the Westminster government has at no point sought to use the powers conferred under this Act to introduce a carrier bag charge in England. ${ }^{14}$ Part of the reason might be that retailers have attempted to persuade a government committed to deregulation that much could be achieved by voluntary action. Coinciding with the Climate Change Act, six major retailers, the British Retail Consortium, the Department of the Environment, Food and Regional Affairs (DEFRA) and the Scottish, Welsh and Northern Irish governments entered into a voluntary agreement to cut the number of carrier bags distributed by the end of May 2009 by 50 per cent (against 2006 levels) and to achieve a 70 per cent cut 'in the longer term'. ${ }^{15}$ This was in fact working with the trend since between 2006 and 2009, plastic bag use in the UK declined by about 40 per cent to under $6.5 \mathrm{bn}^{16}$ as against 2006 when shoppers in the UK were taking home approximately $11 \mathrm{bn}$ plastic bags, equating to more than 400 bags per household or $475 \mathrm{~m}$ plastic bags a month. By May 2009, this agreement had resulted in a 48 per cent reduction across the UK, with a 49 per cent reduction in Wales on the number of single use carrier bags given out. ${ }^{17}$ However, since the recession, plastic bag use is once again on the increase. The British Retail Consortium has accredited this increase to shoppers changing their method of shopping, now making a number of short trips rather than a single big weekly shop. ${ }^{18}$ In Wales, it was felt that progress was insufficient and that further action was required in order to adapt shopping habits to a level of improved sustainable consumption.

Scotland consulted on a mandatory plastic bag charge of 10p in 2005 and had proposed to introduce the Environmental Levy on Plastic Bags (Scotland) Bill but decided not to proceed to legislate amidst doubts about the level of support. As it now revisits the issue, the Scottish government is proposing regulations under s 88 of the Climate Change (Scotland) Act 2009 which provides specific powers to make regulations requiring retailers to charge for carrier bags with the proceeds from the charge going to the advancement of environmental protection or improvement.

In Northern Ireland an initial consultation process closed in October 2011. Following the Welsh example, government in Northern Ireland consulted on the types of retailers to be covered by the charge, what type of bag should be included, the level of the charge/levy

13 The National Assembly's competence to legislate on these topics is found in Matters 6.1, 6.3 and 6.4 contained in Field 6 of Part 1 of Schedule 5 to the Government of Wales Act 2006 as extended by the National Assembly for Wales (Legislative Competence) (Environment) Order 2010.

14 Though in September 2011, the Prime Minister, David Cameron, did warn retailers that they had to reduce the number of plastic bags they distributed or in the future a statutory ban on plastic bags or a mandatory charge may be introduced. See, "Cameron Threatens New Law Following "unacceptable" Rise in Plastic Bag Use', The Guardian, 29 September 2011.

15 ENDS Report 428, Carrier Bag Cuts behind Target, 28 September 2010, 19-20.

16 BBC, 8 September 2011, 'Plastic bag ban "could be considered”, minister says' <www.bbc.co.uk/news/ukpolitics-14841492>.

17 WG (n 5).

18 'Plastic Bag Use on the Rise after Years of Decline', The Guardian, 28 July 2011 <www.guardian.co.uk/ environment/2011/jul/28/plastic-bag-rise>. 
and enforcement and sanction provisions. The consultation proposal, which remains, is that the funds raised from the charge will be forwarded to the government ${ }^{19}$ whereas it is recommended that the funds raised by the charge in Wales are distributed to charities. Consultation on the draft Single Use Carrier Bags Charge Regulations (Northern Ireland) 2012 has recently concluded and a two-phase programme of charging is recommended with a 5p levy on single use carrier bags, effective from April 2013 in phase 1. From April 2014, in phase 2 the levy will be increased to $10 \mathrm{p}$ and extended to lower-cost reusable bags. ${ }^{20}$ In Northern Ireland, in an independent survey of consumers, carried out for the Department of the Environment, 66 per cent of those surveyed said they would welcome a bag levy. In contrast, 42 per cent of businesses identified additional charges for their customers during a period of recession, while 46 per cent of consumers expressed concern at the prospect of having to buy bags. ${ }^{21}$

The experience of the Republic of Ireland suggests that a levy can quickly reduce plastic bag use, which fell from an estimated 328 per person to 21 per person with the introduction of the measure in 2002. However, the charge rose rapidly following its introduction. Since 2002, the Irish government has increased the charge from $€ 0.15$ to $€ 0.22$. Under the Waste Management (Landfill Levy) Regulations 2011, ${ }^{22}$ the plastic bag levy can be amended once in any financial year by the application of the consumer price index plus an additional 10 per cent at the discretion of the Minister for the Environment. The ceiling for the plastic bag levy is set at $€ 0.70$. The levy was increased as a rise in bag distribution had occurred from 21 bags per capita to 31 bags per capita and following the heightened levy, per capita bag usage fell back to 21 . However, an unintended consequence of the levy in Ireland was an increase of around 75 per cent in sales of bin liners and refuse sacks after the levy was introduced, as fewer people used carrier bags as bin liners. ${ }^{23}$

One notable feature of the move to limit bag use is that it is an increasingly rare example of environmental regulation not mandated by the EU. However, the issue is now on the EU environmental agenda. Janez Potočnik, European Commissioner for Environment, introducing an EU consultation has argued that:

Fifty years ago, the single-use plastic bag was almost unheard of - now we use them for a few minutes and they pollute our environment for decades. But social attitudes are evolving and there is a widespread desire for change. ${ }^{24}$

From May until August 2011, the European Commission held the consultation on whether to tax or simply ban plastic carrier bags The consultation, open to the public, organisations and public authorities, asked if charging and taxation would be effective, or if other options such as an EU-level ban on plastic carrier bags would be a better regulatory option. ${ }^{25}$ The consultation also aimed to gather views on the adequacy of current requirements on compostability and biodegradability of plastic carrier bags as provided in the EU Packaging

19 Department of the Environment, Northern Ireland, Proposals for a Charge on Single Use Carrier Bags, 20 July 2011 , at 7.

20 Department of the Environment Northern Ireland, Consultation Document: The Draft Single Use Carrier Bags Charge Regulations (Northern Ireland) 2012, 16 April 2012.

21 'Consumers Give Green Light to Plastic Bag Tax', Belfast Telegraph, 9 December 2011 $<$ www.belfasttelegraph.co.uk/business/business-news/consumers-give-green-light-to-plastic-bag-tax16088785.html>.

22 SI No 434/2011.

23 M Brennan, 'Shoppers Still Bagging Plastic Sales', Irish Examiner, 29 January 2003.

24 European Commission, 'Commission Seeks Views on Reducing Plastic Bag Use', Press Release IP/11/580, 18 May 2011.

25 Ibid. 
Directive. ${ }^{26}$ That Directive makes no clear distinction between biodegradable products that should biodegrade in natural conditions in the environment and compostable products that only biodegrade in industrial composting facilities. Therefore, the consultation proposed that each plastic bag should carry a label clearly defining whether it is 'biodegradable', meaning that it will biodegrade in natural conditions in the environment; or whether it is 'compostable', meaning that it will break down only in industrial composting facilities.

The European Commission acknowledged that some member states had already taken action to reduce the use of plastic carrier bags through: pricing measures (Republic of Ireland, Germany, Denmark); agreements with the retail sector (UK); and bans on certain types of bags (Italy, France). However, no specific measures exist at the EU level, though in March 2011 EU Environment Ministers discussed the environmental impact of plastic carrier bags and the concerns they raised indicated that effective EU action is needed. At the end of the consultation, over 15,500 responses had been received and approximately 53 per cent of respondents 'strongly agreed' with the most stringent measure proposed, namely an $\mathrm{EU}$ ban on plastic bags. In addition, a total of 65 per cent of people strongly agreed that some form of measure needed to be adopted at EU level to reduce the use of plastic bags. ${ }^{27}$

It may be then that UK legislation in this area needs to be adapted at some future point to meet a harmonised EU solution. For the moment, however, three of the four UK administrations look likely to tackle the issue of retail bag use in some way. However, the outcome may be four different carrier bag schemes across the UK. As many retailers operate across the UK, they may have to introduce different systems for their shops in Wales, Scotland, Northern Ireland and England. One national retailer interviewed during our survey, which is outlined below, commented: '[We are] not going to change our bags, we are a massive organisation with only a couple of stores in Wales so not going to change just for Wales.' We now turn to review the Welsh experience.

\section{The carrier bag charge in Wales}

As from 1 October 2011, retailers located in Wales or delivering goods to someone in Wales by single use carrier bags are required to charge a minimum of $5 p$ for all single use carrier bags (reg 6) whether in store and online sales (reg 4). The charge applies to a wide range of retailers from high street to local shops, from market stalls to charities, from takeaway restaurants to opticians. ${ }^{28}$ Under the Regulations, a single use carrier bag is defined as one made from paper, plant-based material or natural starch and is not manufactured for multiple use (reg 3(2)) or is made from plastic, not intended for multiple use and is not classified as a 'bag for life' (reg (3)(3). Under reg 7 and Schedule 1, specific bags are exempt from the charge including: cloth, jute, cotton, hessian, hemp, wicker and heavy duty plastic. Also exempt are bags for unwrapped food items such as fruit and vegetables, bags for uncooked raw meat and fish or small flat paper bags for greeting cards. One particular exemption is for items provided on a prescription or as part of another NHS service

The exemptions are a source of misunderstanding and confusion. Under the Regulations, an exempt bag may lose its exempt status if goods, which do not qualify under Schedule 1, are also put into the exempt bag. The Regulations are aimed at the retailer who distributes a single use carrier bag and therefore, the exemption is lost when, in a single transaction, goods which do not fall under Schedule 1 are put into a bag with the Schedule 1

26 European Parliament and Council Directive 94/62/EC of 20 December 1994 on packaging and packaging waste.

27 E Gyekye, 'Public Strongly Agree with EU Bag Ban Plans', Packaging News, 12 January 2012.

28 See Annex 1 for the full list. 
goods. In a pharmacy, for example, if prescription goods (identified under Schedule 1) are put into a bag, the bag is exempt and no charge applies. However, if the customer is also buying other items, for example, shampoo or moisturiser (goods not included under Schedule 1), and these items are also put into the bag, the bag is no longer exempt and a charge ought to apply. This type of problem can occur in other situations. Bags provided where a shop provides a service, for example, shoe repair, are exempt and not subject to a charge, but if the business also provides goods such as shoe polish it will need to charge for the bag. ${ }^{29}$ The Regulations only allow for a bag to be charged for once. Consequently, where charities give out bags that have already been used, the shoppers would not need to pay the charge on those bags.

The record-keeping requirements on retailers are quite onerous as a record must be kept of: the number of single use carrier bags supplied which meet the requirements of the charge; the gross amount collected from the charge; the net proceeds, minus VAT liability and any other reasonable costs; and how the net proceeds have been distributed. However, by amending regulations, retailers with fewer than 10 employees are exempt from the requirement to keep records. Nonetheless, if they are VAT registered they are still required to pay all VAT liabilities arising from the charge and consequently will need to keep records for this purpose. Any retailer who does not charge for a non-exempt single use carrier bag, or fails to keep, retain, supply and publish records (where required) is in breach of the regulation (reg 11) and could face civil sanctions of a fixed penalty of up to $£ 200$ (Schedule 2) or a discretionary penalty up to $£, 5000$ or up to $£ 20,000$ if they provide false or misleading information (Schedule 3). Local Authorities are responsible for administering and enforcing the charge (reg 5). They are permitted to make test purchases of goods for the purposes of ascertaining whether the retailer is complying with the Regulations (reg 14(2)(a)). The Regulations do not provide any requirement on the final destination of the charge, but the WG has recommended that the proceeds are passed on to good causes in Wales, ${ }^{30}$ though there is no requirement on the retailers to disclose the decisions they make about how they use the additional funds generated by the obligation to charge (reg 8).

\section{Public attitudes to charging}

In mid-September 2011, a team of researchers from the ESRC BRASS ${ }^{31}$ Research Centre at Cardiff University investigated the introduction of the new charge in Wales in two distinct but inter-related phases. Phase I was an analysis of the attitudes, awareness and acceptance of the charge by the public, whilst phase II was an assessment of the attitudes of retail companies, their level of understanding of the regulations and WG guidance, the practicalities of introducing the charge (including staff-training and record-keeping) and questions relating to the proceeds from the charge. The first phase of this work is now considered.

Face-to-face surveys of 600 members of the public were conducted at four different sites across Cardiff in mid-September 2011. The interviewees were randomly selected by a group of surveyors. The four sites were chosen to capture respondents within an area which offered as a wide as possible selection of retail outlets within the city. The four sites captured potential and/or actual shoppers from brand-name stores, supermarkets, fast-food and takeaway outlets, clothing and charity shops as well as market stalls in both local and city-centre locations. Demographic information relating to gender, age group and employment status/sector was collected in addition to a further 10 questions on the level

29 WG, Guidance on the Single Use Carrier Bag Charge (Wales) Regulations 2010, September 2011, para 21.

30 WG, Retailer Information Pack, Single Use Carrier Bag Charge: Key Points (WG 2011).

31 ESRC Research Centre for Business Relationships, Accountability, Sustainability and Society (BRASS) at Cardiff University of which both authors are members <www.brass.cf.ac.uk>. 
of awareness of the introduction of the charge, ${ }^{32}$ whether interviewees knew the extent of the charge in relation to shops and types of bag included. Respondents were further asked whether and why they agreed or disagreed with the charge and why they believed the WG had introduced such a charge. They were also asked what maximum charge they would be willing to pay for carrier bags.

The survey sample was not a proportional representation of the population of either Wales or Cardiff. It was based on a random selection of 600 people in Cardiff who were willing to complete the survey questionnaire. The sample does represent, however, a close proportional representation of the Wales gender demographics, which is 51 per cent female and 49 per cent male as against the survey sample which was 54 per cent female and 46 per cent male. ${ }^{33}$ In Cardiff by June 2010, the population between the age of 16 and 64 (excluding students) was 196,800. Of this figure 79 per cent was employed (the survey captured 43 per cent) and 8 per cent unemployed (the survey captured 6 per cent). Given the time of day of the survey (mid-morning to mid-afternoon), the number of employed respondents is likely to be less than the Cardiff employment percentage. In 2009, the WG estimated that in Cardiff 16 per cent of the population was of retirement age (SDR 40/2009, Statistical Focus of Age in Wales, 2009). Of the people in the survey sample, 19 per cent classified themselves as retired.

There was a high level of awareness of the forthcoming charge with 85 per cent of all respondents stating that they were aware that a carrier bag charge was to be introduced. However, of those who were aware, only 41 per cent knew that the charge would commence on 1 October 2011 (within two weeks of the survey taking place). Moreover, more detailed knowledge of the charge was often lacking. 60 per cent of respondents (wrongly) believed that the charge applied only to plastic carrier bags and although 51 per cent identified (correctly) that the charge would apply to all types of shops, 27 per cent believed that it applied to supermarkets only. There was widespread support for the charge, with 70 per cent of the respondents agreeing with the introduction of the charge, and only 26 per cent disagreeing. The remaining 4 per cent had either no view, were undecided or were not interested.

Of the 70 per cent who agreed with the charge, ${ }^{34}$ they cited as their main reasons for support: the positive impact on the environment; improved litter control; and a reduction in the use of plastic bags as well as a general reduction in waste generated. Many within this group defined environment as their local surroundings and linked environment to improved litter control. There was little appreciation of wider environmental issues such as resource use or indeed that the move might be linked to such issues as emissions' reductions and wider issues of climate change as reflected in the 2008 Act. ${ }^{35}$

Of the 26 per cent who disagreed with the charge, the main reason given was the additional cost on already expensive food bills. There was also a feeling that the charge should not apply to items such as clothes or expensive goods as a carrier bag was a part of the retail service experience. Interestingly, 38 per cent of respondents said that they were

32 On the whole attitudes based on gender, age, etc are not examined in the analysis presented here, which deals with broad questions of attitudes to the charge.

33 All statistics here taken from StatsWales $2010<$ http://statswales.wales.gov.uk/index.htm>.

34 This figure seems remarkably resilient as it matches that in a study published in June 2012 of attitudes to the charge: see W Poortinga, L Whitmarsh and C Suffolk, Evaluation of the Introduction of the Single-Use Carrier Bag Charge In Wales: Attitude Change and Behavioural Spillover, Report to Welsh Government by Cardiff University, June 2012.

35 Cf the comment by one respondent: "No need to introduce [it], climate change is happening and we can't stop it." (Interviewee 242). 
willing to pay more than $5 \mathrm{p}$ for a carrier bag, though for some this did depend on the quality of the bag, and 29 per cent said 5p was the maximum amount they would pay. A further 24 per cent said that they would be unwilling to pay at all for a bag but this did not necessarily indicate distaste for the policy but meant that it was their firm intention to shop with their own reusable bag and therefore never make a payment. Only 11 per cent of respondents said they were likely to buy bags, ${ }^{36}$ with 67 per cent indicating an intention to use their own bags. There was an identifiable link between willingness to pay and the use to which payments would be put. This might well influence behaviour in Northern Ireland where revenues will return to the government rather than the charitable sector, which is often the case in Wales. In the survey, 13 per cent believed that the reason the charge had been introduced was to raise money for the WG. It was viewed (wrongly) as a tax or as a means of dealing with the economic climate by bringing in additional public revenue. Few respondents knew that the funds would not be returned to government, but respondents did feel that they would be more willing to pay the charge if they were assured that the funds would be distributed to charities. ${ }^{37}$

In summary, whilst the majority of the public surveyed knew about the charge and were in agreement with it, many of the respondents were hazy on the detail, for example, believing that the charge applied solely to plastic carrier bags. In addition, respondents in favour of the charge still expressed concerns about the reasons why the WG was introducing it and were unaware that the funds would not be returned to the government but that the government had recommended that the funds be given to charities. Respondents aware that the funds were to go to charity were generally supportive of the charge. Local charities in particular seem to have been beneficiaries of the revenues generated by the Welsh scheme and recognition of this, following the introduction of the scheme, appears to have helped public acceptance of the charge. In spite of the fact that there is no legal requirement to forward the proceeds of the charge to charity, the majority of retailers do so and make something of a virtue of this. Again it will be interesting to compare the experience in Northern Ireland, but one might expect that there may be less support by both retailers and consumers for what could be seen as a revenue-raising measure.

\section{Retailer reactions}

Phase II of the work was a business survey conducted one month after the public survey (Phase I) in mid-October 2011 and was spread over a two-week period. A database of over 300 companies located in Cardiff was developed from which participating companies were sought. Companies were selected randomly, although a small sub-sample was also identified based on their size to ensure a sample that represented as wide a possible spectrum of the different types of retailers covered by the charge. Retail outlets included bookshops, hairdressers, jewellers, stationers, electronics suppliers and the like as well as departmental stores and food outlets. The latter category itself was wide ranging covering takeaways, bakers, butchers, fruit and vegetable shops, greengrocers, health food shops and off-licences.

The sample also included a broad spectrum of company sizes but did pay particular attention to small to micro-sized organisations as they represent the largest percentage of

36 In the event the food retail sector has seen reductions of between 95 per cent and 70 per cent according to the British Retail Consortium: see John Griffiths AM, Written Statement: An Update on the Single Use Carrier Bag Charge in Wales (WG, 4 July 2012).

37 Reported figures of charitable donations from supermarkets in Wales included $£_{13} 6,352$ from Asda (as at end April 2012, and $f_{1} 170,642$ from Morrisons (as at 6 April 2012) <http://greenroom.asda.com/2012/6/20/ wales-air-ambulance-benefit-from-carrier-bags > and <www.morrisons.co.uk/corporate/CR/Our-carrier-bagsavings-in-Wales $/>$. 
companies in Wales. ${ }^{38}$ The size of company was measured by the full-time equivalent (FTE) staff for each site, however, 59 per cent of the retailers interviewed did belong to a group of shops, though some may have had only one or two other small shops in other locations in Wales; others, including the charities, belonged to larger organisations that spread across the UK. Overall, companies were willing to participate and the target of 50 companies was surpassed with survey data being collected from 90 retailers across Cardiff. The interviews were conducted either face to face or, where more convenient for the company, by telephone. Surveyors sought information on how the charge had been introduced by each company and also views of how the public appeared to be responding to the charge.

Once again, the survey sample was not a proportional representation of the population of retail stores in either Wales or Cardiff. It is a random selection of retail stores located in Cardiff based on type of store and size of store. The data was not grossed up to represent the findings of retail stores in general and is therefore only an indication of the 90 stores surveyed. Of the retailers surveyed, 59 per cent belonged to a chain of stores, with 52 per cent being small-scale chains based solely in Wales.

The data was collected using a standard questionnaire based on information that would reflect the key elements of the obligation placed on the companies by the introduction of the charge. This included data on: charging practices; identification and use of exempt bags; administration of the charge; level of information received and used; destination of proceeds; and customer reactions to the charge. All data collected from the retail stores was gathered in confidence and anonymised to conceal the identity of the companies who agreed to participate in the survey and to ensure appropriate data protection. The data was amalgamated to provide an overall percentage response from the 90 Cardiff retailers participating.

One immediately surprising finding was how little lead-in time many of the companies had had to prepare for the change with almost half of our respondents (48 per cent of companies) claiming to have learnt of the charge only one to two months prior to its introduction. The majority of the respondents (31 per cent) stated that their main source of information about the charge came from the media or news outlets. Just 18 per cent of respondent retailers had been informed about the charge by the WG either in the form of a letter or from the website, though this percentage may be a little artificial: 16 per cent were informed directly by their Head Office, which may well have obtained the information from the WG rather than from a trade association or the media. As many of the head offices of larger stores were based in England, many of the Welsh stores had not received the information directly from government. One consequence of this was that those responsible for introducing the charge in Wales only had partial information about how the charge would operate.

Only 7 per cent of retailers were charging for carrier bags prior to the 1 October 2011. ${ }^{39}$ In contrast, 94 per cent of Welsh retailers are now charging the minimum price of $5 \mathrm{p}$. Some retailers did state that this did not cover the purchase cost of the bag to the company, potentially indicating that they were unaware that the $5 \mathrm{p}$ charge was merely a minimum and that they were able to set a higher charge; and 3 per cent of retailers are charging more than

38 In the 2010 Size Analysis of Welsh Businesses, 60 per cent were identified as micro, small and medium-sized enterprises, SDR 180/2010, released 20 October 2010. In Cardiff, the size breakdown identified that 96.7 per cent of all businesses were identified as micro, small and medium. These figures apply to all business types and not just retail companies.

39 In evidence to government in Northern Ireland, Marks and Spencer disclosed that it introduced a 5p food carrier bag charge in May 2008 aiding a reduction in food bag usage by 80 per cent (or 1.7bn bags) as well as generating nearly $f_{6} 6 \mathrm{~m}$ to charitable projects across the UK: see consultation response letter of 14 June 2012: <http://corporate.marksandspencer.com/documents/publications/consultations/ni_carrier_bags_2012.pdf>. 
5p (between 6p and 10p) and 3 per cent admitted that they were not charging. The reasons provided by the latter group included that: the standard of the bag was of the same quality and description as a bag for life and therefore no charge was required under the legislation; the retailer no longer provided any kind of carrier bag; or customers were asked to make a donation to a charity. Only one company did state that they would not be charging, despite knowing that their bags fell within the regulations.

As explained above, the status of exempt bags is complex. Whilst 45 per cent of the sample stated that they did not have any exempt bags, 35 per cent of these were retailers of the type that one might expect to have some form of exempt bag either because they may sell loose food products (grocers), items that fit into small flat bags (card shops) and those that may reuse bags (charities). This therefore suggested doubts about the level of understanding amongst the companies as to what constituted an exempt bag. Some did state that they would charge for a bag irrespective of its status because they did not want to be prosecuted. ${ }^{40}$ Of the 54 per cent of companies who stated that they distributed exempt bags, 32 per cent reported that customers were confused about how the exemption operated, in particular in relation to food items.

There was confusion also over what information had to be recorded, particularly in relation to 'reasonable costs' that could be deducted from the gross amount collected from the charge. Some retailers thought that they could deduct their purchase cost of the bag, which under the regulations is not permitted; and other retailers were merely operating a 'coin in box' system, which was then handed over to a charity. However, if these companies were VAT registered, they risk a breach of their obligations to pay VAT on the carrier bag charge since the sale of the bag attracts VAT. In fact 54 per cent of the companies were not aware of their VAT obligation, although for many this was administered centrally and therefore was not something they had themselves to consider. Only 7 per cent of companies stated that they would send the proceeds to environmental causes. The WG had stated that it hoped that the proceeds would be passed on to good causes in Wales, in particular environmental projects. However, whilst the majority of retailers were passing on the proceeds to charity, environmental causes were not the main recipients. In Scotland, legislation will allow for the Scottish ministers to direct net proceeds (i.e. profit after administrative costs have been deducted, estimated at $f, 5-6 \mathrm{~m}$ if an 80 per cent drop is achieved) to be used for 'environmental protection or improvement or to any other purposes that may be reasonably regarded as analogous. ${ }^{41}$

Of those retailers who sold bags for life or other non-single use carrier bags (canvas, hessian or cotton), a minority of stores reported a significant (500 per cent-plus) increase in their distribution since 1 October 2011. The majority of the other stores either stated that there was no change or that sales had increased between 20 and 50 per cent. It should be noted that a distorting factor here is that a number of stores were handing out free bags for life prior to and during the first few weeks of the introduction of the charge. Of the retailers who provided an estimate of how many customers were bringing their own bag, the estimate varied between 20 and 95 per cent of customers coming prepared with their own bag. Those companies that reported significant increases between 60 and 95 per cent were mainly supermarkets and department stores in comparison to charities, book and clothing shops which reported an increase of less than 60 per cent. Nonetheless, 66 per cent of companies did report a reduction in carrier bags. The reduction varied from a slight

40 Anecdotal experience of those living or working in Wales bears this out. It is not uncommon to be asked to pay for clearly exempt bags.

41 Scottish Government, Consultation on a Programme to Encourage the Sustainable use of our Resources, to Support both the Environment and Economy, 27 June 2012. 
reduction up to approximately 95 per cent with those reporting a reduction of more than 80 per cent being the larger national retail chains. Those recording a reduction between 50 and less than 80 per cent were predominantly charities. Companies reporting a reduction of less than 50 per cent were a mixture of charities and clothes shops. Greengrocers reported only a slight decrease in carrier bags, as did pharmacies and electrical stores. Takeaways, however, did not record any reduction.

\section{Conclusion: communicating change}

In one sense the introduction of a charge for carrier bags was not the most difficult exercise in law reform. It had widespread support and there was a good deal of awareness of the impending change. Though an essentially simple regulatory measure in the form of a ban on freely available single use bags, much of the detail of the change was misunderstood in terms of essentials such as what type of bags and which shops would be subject to the charge. Moreover, in spite of public goodwill, very few people were aware that the money could go to charity, with a significant minority of people (13 per cent) believing that this charge was introduced for financial or economic reasons.

There was a widespread belief that the charge was restricted to plastic carrier bags but it was a rather unique feature of the Welsh policy that the charge would be levied on other sorts of bags, such as paper bags. Retailers later reported much stronger levels of consumer resistance when this was realised. Retailers themselves had poor understandings of the detail of the regulation, in particular regarding the use of bags exempt from the charge and, more seriously, in relation to the VAT implications of adding a charge for a bag. This was because, in spite of attempts by the WG to brief retailers by sending out 40,000 information packs, the majority of retailers surveyed in the research reported receiving no official information about the charge. They were reliant on the media or other retailers for the information. This was true also of the shoppers who had heard about the charge from either the media (television, radio and newspapers at 38 per cent) or from shops and supermarkets $(33$ per cent). Moreover, only 6 per cent had heard about the introduction of the charge from the government-led advertising campaigns with more people (8 per cent) reached by word of mouth. This suggests that, both in the case of retailers and shoppers, the best route to dissemination to those affected by regulation is likely to be via media briefings.

Policymakers may find it helpful to try and communicate some of the finer detail where a measure such as this affects the wider public. Although there was broad knowledge of the charge and good acceptance of it, support improved where the environmental benefits of the scheme and understandings of its charitable nature were better understood. In communicating this sort of change, policymakers may need to understand that government itself is unlikely to be the first source of information either for those directly regulated (in this case retailers) or otherwise affected (as with the shoppers). If other forms of media are the main source of information, policymakers may need to take this into account. For example, the survey shows that knowledge of the change was much higher among older shoppers (over 55s) and much lower among young people. Policymakers may need to consider the types of media accessed by certain age (or other types of) groups.

The uncertainty among retailers, regarding the detail of the regulation, did give rise to difficulty. It was never the intention of the WG to immediately deploy the penalties and sanctions in the legislation for failure to adequately implement the charge. However, misunderstandings concerning potential liability for VAT might not be dealt with only by the WG and, with VAT at 20 per cent, a failure to hold back a penny when making a charge for a carrier bag might have serious consequences for the regulated community when faced with a VAT bill. It would seem that of the $£ 400,000$ said to have been spent on 
communicating the measure, money may have been better spent securing media coverage of the change than in trying to reach the retail community directly with information packs. Our research suggests that 41 per cent of the retailers surveyed had become aware of the measure in the two months prior to its introduction. This probably followed heightened media discussion of the issue but it meant a short lead-in time to respond to the regulation for those retailers. Earlier media briefings would have certainly been helpful to this body of respondents (which were generally small and medium-sized enterprises).

Nonetheless, the policy should be considered a success and has been assessed as popular and effective in a survey of attitudes towards the charge. ${ }^{42}$ The habit of taking one's own bag to the shop has increased across all age and gender groups. The carrier bag charge attracted widespread support before its introduction and there is no sign that this has diminished. ${ }^{43}$ Indeed, rather than the public resenting the non-availability of free bags, the policy has attracted support because the general public appear to have responded by retaining their own bags particularly for supermarket shopping. The charitable underpinnings of the scheme have helped maintain popular support.

The ban on carrier bags has been described as a cuddle blanket that was briefly, and horribly, fashionable. This is not quite true since, with measures still to come in Northern Ireland and Scotland, it seems still to be in fashion. But the same commentator ${ }^{44}$ also described the measure as a deadly distraction, presumably because there are more serious environmental threats about which we should worry and which might more fittingly be the subject of legislation. This is undoubtedly so, but it ignores the rhetorical quality of the measure in Wales as a sign of an intent to begin tackling some of these wider problems. However, if the ban on single use bags is more important for its symbolism than its environmental impact, then this might be considered all the more reason why communication of the measure to both retail organisations and the wider public mattered so much and, judging by the results of the surveys, an opportunity to engage on a green agenda was poorly exploited.

42 Poortinga et al (n 34).

43 Ibid.

44 T Gold, 'This Plastic Bag Conspiracy is a Truly Deadly Distraction', The Guardian, 3 August 2012. 